\title{
Purple urine bag syndrome in benign prostatic hyperplasia patient
}

\author{
Ankit Kayal ${ }^{1 *}$, Shashanka Dhanuka', Bibhas Chandra Mukhopadhyay ${ }^{1}$, Tapan Kumar Mandal ${ }^{1}$ \\ and Charu Lata Bansal ${ }^{2}$
}

\begin{abstract}
Background: Purple color of urine is alarming and may indicate a serious underlying pathology. Purple discoloration of the urinary catheter bag is uncommon and is caused by urinary tract infection with certain organisms.

Case presentation: We present a case of this rare phenomenon in a benign prostate hyperplasia patient with indwelling catheter who also has diabetes mellitus and chronic renal disease. We also discussed proposed etiology and pathophysiology of purple urine bag syndrome.

Conclusion: Attempt to make the patient catheter free after stabilizing the patient is also the key point in its management. Although purple urine bag syndrome is not an aggressive pattern, it is an indicator for urosepsis.
\end{abstract}

Keywords: Purple urine bag syndrome, Benign prostate hyperplasia, Chronic renal disease, Diabetes mellitus

\section{Background}

Purple urine bag syndrome (PUBS) is the color of the urine bag rather than discoloration of urine following urinary catheterization for hours and days (Figs. 1 and 2). Risk factors are urinary tract infection due to various pathogens, including Escherichia coli, Klebsiella, Morganella, Citrobacter, Proteus mirabilis, and Providencia (rettgeri and stuartii) [1]. Predisposing factors are chronic constipation, use of laxatives, prolonged urinary catheterization, alkaline urine $\mathrm{pH}$, tryptophan-rich foods, renal failure, and cognitive disorders. Dehydration, hypovolemia, elderliness, and female sex are other risk factors for PUBS. Tryptophan is converted to indigo (blue) or indirubin (red) by sulfatases or phosphatases produced by urinary bacteria. Because these pigments are insoluble, they are attached to a urine bag or catheter, causing purple urine bag syndrome. Mild or asymptomatic infection can also occur with bacteriuria [2] (Tables 1 and 2).

\section{Case presentation}

Our patient was a 65-year-aged male patient presented with chronic urinary retention due to $\mathrm{BPH}$. He also had

\footnotetext{
* Correspondence: ankitkayals@gmail.com

'Department of Urology, NRS Medical College and Hospital, Kolkata, India Full list of author information is available at the end of the article
}

deranged kidney function, uncontrolled diabetes, hypertension, and chronic constipation, but the patient was ambulatory. USG confirmed $80 \mathrm{~g}$ prostate with bilateral hydroureteronephrosis. Initial serum creatinine was $5 \mathrm{mg} / \mathrm{dl}$, serum potassium level was $5.5 \mathrm{mmol} / \mathrm{l}$, electrocardiography findings was normal, serum prostatic specific antigen level was $2.3 \mathrm{ng} / \mathrm{dl}$, blood sugar fasting was 180 , and postprandial was $250 \mathrm{mg} / \mathrm{dl}$ on oral hypoglycemic. Catheterization was done as there were upper tract changes due to chronic retention. After endocrinology consultation, insulin was started and a cardiologist added two antihypertensive drugs while a nephrologist performed two sittings of hemodialysis. On subsequent visits, his blood sugar was well controlled, and blood pressure and kidney function were stable after 1 month of initial presentation. After 1 month, catheter change was done and the patient is planned for operation and advised to continue tamsulosin and dutasteride combination and laxative till enlistment for admission and operation which usually takes 1 month in our setup.

During his planning for operation, after 2 weeks, the patient presented with discoloration of urobag which was purple in color. Neither fever nor pain was noted in between the period. The patient did not take any other new medication or change his routine diet in the last 2 weeks. Hemoglobin was $9 \mathrm{~g} / \mathrm{dl}$, total leucocyte 


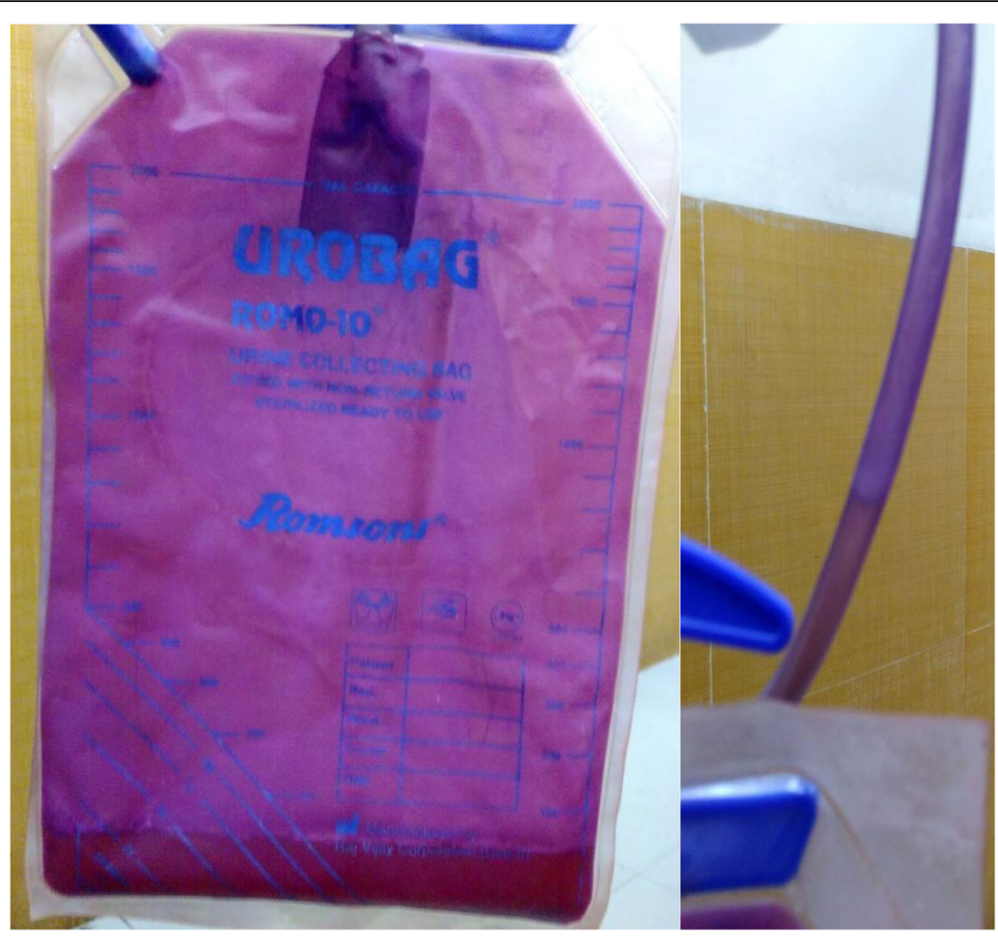

Fig. 1 Purple color urobag and tubing in the case of PUBS

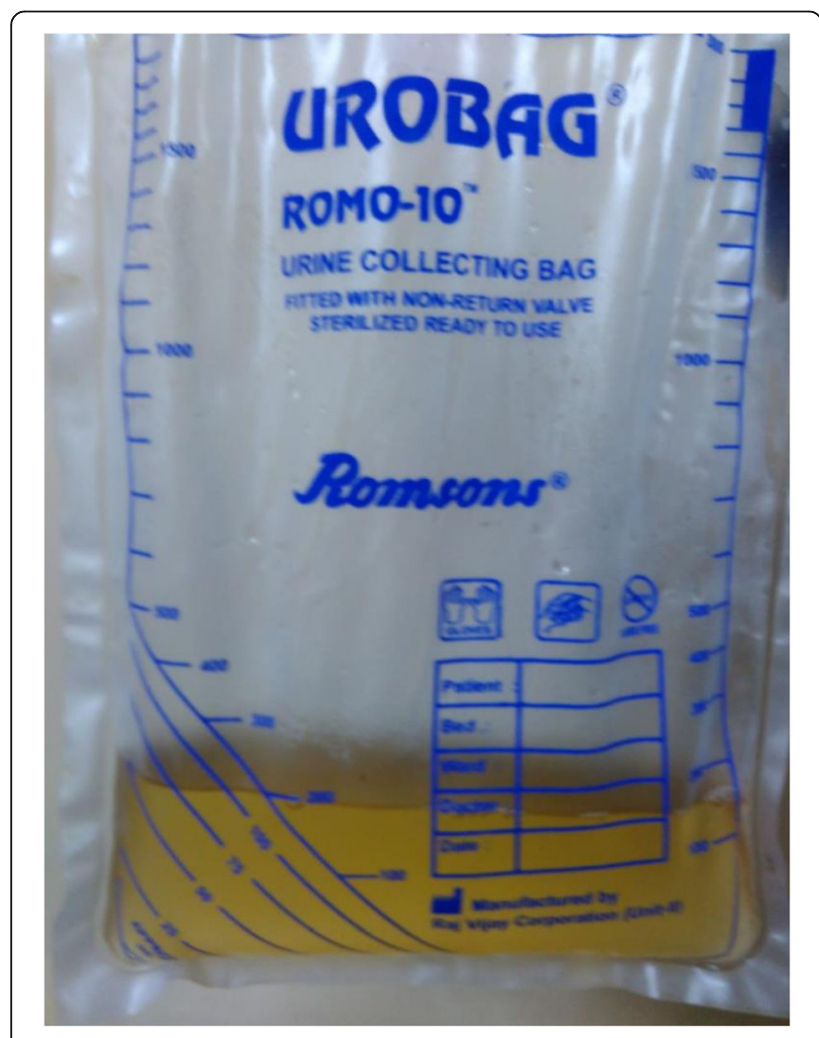

count was $8000 / \mathrm{mm}^{3}$ on urine examination, and it was alkaline and culture growth that show Pseudomonas and E. coli. This was sensitive to levofloxacin. Oral levofloxacin antibiotic was given for 14 days, and catheter change was done.

Subsequently, the patient got well, and after 1 month, the patient got operated for $\mathrm{BPH}$ and become catheter free. During 3 months of follow-up, he was doing well.

The patient was male and ambulatory with controlled $\mathrm{DM}$, hypertension, and $\mathrm{BPH}$ with chronic retention which makes our case different and rare.

\section{Clinical course}

When ingested, tryptophan gets exposed to intestinal flora in patients with altered gut flora and these pigments

Table 1 Risk factors associated with PUBS

Female gender

Dementia (cognitive impairment)

Alkaline urine

Constipation

Chronic catheterization with indwelling catheters

High bacterial loads in the urine

Chronic kidney disease

Diabetes mellitus

Immunocompromised status

Fig. 2 Normal urine color 
Table 2 Commonly associated bacteria with purple bag syndrome

Citrobacter species, including C. freundii, C. diversus, and C. koseri
Enterobacter species, including E. aerogenes, E. agglomerans,
and E. cloacae
Enterococcus species, including E. avium and E. faecalis
Escherichia coli
Klebsiella pneumonia
Morganella morganii
Proteus species, including P. mirabilis and P. vulgaris
Providencia species, including P. rettgeri and P. stuartii
Pseudomonas aeruginosa
Methicillin-resistant Staphylococcus aureus

evolve. In constipated patients, delayed gut transport allows coliforms to deaminate tryptophan to indole, and after absorbtion from the gut, it conjugated in the liver to form indoxyl sulfate. Urinary tract infection causes bacteria to produce indoxyl sulfatase, depending on urine $\mathrm{pH}$ and oxygen concentration which degrades indoxyl sulfate to indigo (high $\mathrm{pH}$ ) and/or indirubin (low oxygen). The color of the bag turns to purple, due to the mixture of indigo (blue violet) to indirubin (red violet) that gives the purple color.

Enlarge prostate leads to chronic retention that land up into back pressure changes to the kidney causing renal failure, and associated diabetes make kidney more susceptible to uremia and make the bowel movement sluggish. Usually, indoxyl sulfatase is normally excreted in urine, but in uremic patients, its excretion raised markedly due to impaired renal clearance. Due to toxins in uremic patients, there are chances to increase aerobacteria such as E. coli and decrease anaerobacter such as bifidobacteria in the intestine. Indole is chiefly produced by the aerobe which is the chief precursor of indoxyl sulfate. Raised serum indoxyl sulfate causes raised urinary indoxyl sulfate. Even after hemodialysis, protein-bound indoxyl sulfate is difficult to wash out. This explains the probable pathophysiology of our case (Additional file 1). The clinical course of PUBS is not aggressive if treated with proper antibiotic in time and if the catheter is changed.

\section{Review of literature}

The physical examination of the urine includes an evaluation of color, turbidity, specific gravity and osmolality, and $\mathrm{pH}$. The color identification does not require any especial series of test; it is simply determined by the naked eye in a clear glass test tube. The normal color of urine is pale yellow due to the presence of the pigment urochrome [3]. Mostly, urine color variation is due to its
Table 3 Common causes of abnormal urine color

\begin{tabular}{|c|c|}
\hline Color & Cause \\
\hline \multirow[t]{2}{*}{ Colorless } & Very dilute urine \\
\hline & Overhydration \\
\hline \multirow[t]{3}{*}{ Cloudy/milky } & Phosphaturia \\
\hline & Pyuria \\
\hline & Chyluria \\
\hline \multirow[t]{7}{*}{ Red } & Hematuria \\
\hline & Hemoglobinuria/myoglobinuria \\
\hline & Anthocyanin in beets and blackberries \\
\hline & Chronic lead and mercury poisoning \\
\hline & Phenolphthalein (in bowel evacuants) \\
\hline & Phenothiazines (e.g., Compazine) \\
\hline & Rifampin \\
\hline \multirow[t]{3}{*}{ Orange } & Dehydration \\
\hline & Phenazopyridine (Pyridium) \\
\hline & Sulfasalazine (Azulfidine) \\
\hline \multirow[t]{3}{*}{ Yellow } & Normal \\
\hline & Phenacetin \\
\hline & Riboflavin \\
\hline \multirow[t]{8}{*}{ Green-blue } & Biliverdin \\
\hline & Indicanuria (tryptophan indole metabolites) \\
\hline & Amitriptyline (Elavil) \\
\hline & Indigo carmine \\
\hline & Methylene blue \\
\hline & $\begin{array}{l}\text { Phenols (e.g., IV cimetidine [Tagamet], } \\
\text { IV promethazine [Phenergan]) }\end{array}$ \\
\hline & Resorcinol \\
\hline & Triamterene (Dyrenium) \\
\hline \multirow[t]{7}{*}{ Brown } & Urobilinogen \\
\hline & Porphyria \\
\hline & Aloe, fava beans, and rhubarb \\
\hline & Chloroquine and primaquine \\
\hline & Furazolidone (Furoxone) \\
\hline & Metronidazole (Flagyl) \\
\hline & Nitrofurantoin (Furadantin) \\
\hline \multirow[t]{8}{*}{ Brown-black } & Alcaptonuria (homogentisic acid) \\
\hline & Hemorrhage \\
\hline & Melanin \\
\hline & Tyrosinosis (hydroxyphenylpyruvic acid) \\
\hline & Cascara, senna (laxatives) \\
\hline & Methocarbamol (Robaxin) \\
\hline & Methyldopa (Aldomet) \\
\hline & Sorbitol \\
\hline
\end{tabular}

From [4] 
Table 4 Associated mechanisms of PUBS

Increased available tryptophan substrate for conversion

Alkaline urine facilitates indoxyl oxidation

Increased time for bacterial deamination in constipation and slow gut motility

Female short urethra prone to UTI

Catheter in situ bacteriuria

In UTI, more bacterial sulfatase/phosphatase availability

In uremic patients, impaired clearance of indoxyl sulfate

concentration. Many foods, medications, metabolic products, and infection may also produce abnormal urine color [4] (Table 3). Change of urine color is often noticed by the patient him/herself.

Historically, in 1812, purple discoloration is noticed by a physician in King George III urine who also has chronic severe constipation [5]. But in literature, purple urine bag syndrome was first reported in 1978 [6].

Dealer et al. study stats the incidence of purple bag syndrome mentioned about $9.8 \%$ in institutionalized patients mostly bedridden, cognitively impaired, and constipated females but it very rarely seen in daily practice and very few literature is present $[7,8]$.

Nakayama and Kanmatsuse found that serum levels of tryptophan and valine significantly fell down in PUBS patients. They also documented that amino acid absorption is altered by disturbances of colonic motility and intestinal overgrowth $[9,10]$.

Discoloration of urine is alarming and may be an indicator of early sign of serious underlying pathology. However, most of the cases are benign and occur as a result of ingestions of substances such as medications or food dye or post traumatic instrumentations (Table 4) [11].

Some untreated cases of PUBS also reported high morbidity and mortality especially in immunocompromised and multiple organ disease patients [12].

\section{Discussion and conclusion}

Purple discoloration of the urinary catheter bag is relatively uncommon. And it is caused by urinary tract infection with certain organisms in patients with certain features. Although PUBS is not an aggressive pattern, it is an indicator for urosepsis. The catheter-associated UTI is most commonly seen in females. So PUBS is more common in female patients [1].

To our knowledge, it is the first case in a male patient with chronic urinary retention for $\mathrm{BPH}$ and who has PUBS.

Attempt to make the patient catheter free after stabilizing the patient is also the key point in its management.

\section{Additional file}

Additional file1: Metabolic pathway and proposed pathophysiological mechanism (DOC $39 \mathrm{~kb}$ )

Abbreviation

$\mathrm{BPH}$ : Benign prostate hyperplasia; PUBS: Purple urine bag syndrome; UTI: Urinary tract infection

\section{Acknowledgements \\ The authors would like to express our sincere thanks to Dr. Tapas Majhi for giving us valuable advice and the medical staffs of Nil Ratan Sircar Hospital, Kolkata, India, for collecting samples of the patient and analyzing the samples. \\ The authors also thank Dr. Manak Chand Kayal for his skillful English editing.}

\section{Availability of data and materials}

The data and materials were all included in the manuscript.

\section{Authors' contributions}

AK is responsible for the manuscript. AK and CLB performed the acquisition of the data and interpretation of the data and drafted and revised the manuscript. SD helped to draft the manuscript. BCM and TKM participated in the design and coordination. All authors read and approved the final manuscript.

\section{Funding}

Not applicable. Our manuscript does not contain funding.

\section{Ethics approval and consent to participate}

Written informed consent was obtained from the patient. For this type of case report, formal consent from a local ethics committee is not required.

\section{Consent for publication}

Written informed consent was obtained from the patient for publication of this case report and any accompanying images.

\section{Competing interests}

The authors declare that they have no competing interests.

\section{Publisher's Note}

Springer Nature remains neutral with regard to jurisdictional claims in published maps and institutional affiliations.

\section{Author details}

${ }^{1}$ Department of Urology, NRS Medical College and Hospital, Kolkata, India.

${ }^{2}$ Department of Obs \& Gyne, SMS Medical College and Hospital, Jaipur, India.

Received: 28 June 2017 Accepted: 3 October 2017

Published online: 22 December 2017

References

1. Hadano Y, Shimizu T, Takada S, Inoue T, Sorano S. An update on purple urine bag syndrome. Int J Gen Med. 2012;5:707-10. https://doi.org/10.2147/ IJGM.S35320.

2. Kenzaka T. Purple urine bag syndrome in a patient with a urethral balloon catheter and a history of ileal conduit urinary diversion. Korean J Intern Med. 2015:30:420

3. Glenn S. et al. Evaluation of the urologic patient: history, physical examination, and urinalysis. In Wein AJ et al.(11 eds), Campbell-Walsh urology, Philadelphia: Saunders Elsevier.2016;chap. 1, pp. 13.

4. Hanno PM, Wein AJ. A clinical manual of urology. Norwalk (CT): AppletonCentury-Crofts; 1987. p. 67

5. Arnold WN. King George III's urine and indigo blue. Lancet. 1996 Jun 29; 347(9018):1811-3.

6. Barlow GB, Dickson JAS. Purple urine bags. Lancet. 1978;311:220-1.

7. Dealler SF, Belfield PW, Bedford M, Whitley AJ, Mulley GP. Purple urine bags. J Urol. 1989;142:769-77.

8. Dealler SF, Hawkey PM, Millar MR. Enzymatic degradation of urinary indoxyl sulfate by Providencia stuartii and Klebsiella pneumoniae causes 
the purple urine bag syndrome. J Clin Microbiol. 1988;26(10):2152-6. PMC free article] [PubMed]

9. Harun NS, Nainar SK, Chong VH. Purple urine bag syndrome: a rare and interesting phenomenon. South Med J. 2007;100:1048-50. [PubMed]

10. Nakayama T, Kanmatsuse K. Serum levels of amino acid in patients with purple urine bag syndrome. Nippon Jinzo Gakkai Shi. 1997:39:470-3.

11. Aycock RD, Kass DA. Abnormal urine color. South Med J. 2012;105:43-7.

12. Tasi YM, Huang MS, Yang CJ, Yeh SM, Liu CC. Purple urine bag syndrome, not always a benign process. Am J Emerg Med. 2009;27:895-7. [PubMed]

Submit your next manuscript to BioMed Central and we will help you at every step:

- We accept pre-submission inquiries

- Our selector tool helps you to find the most relevant journal

- We provide round the clock customer support

- Convenient online submission

- Thorough peer review

- Inclusion in PubMed and all major indexing services

- Maximum visibility for your research

Submit your manuscript at www.biomedcentral.com/submit
Biomed Central 